\title{
Modeling endogenous technological change for climate policy analysis
}

\author{
Kenneth Gillingham ${ }^{a}$, Richard G. Newell ${ }^{\text {b,c,d,* }}{ }^{\text {, William A. Pizer }}{ }^{\mathrm{c}}$ \\ a Stanford University, Stanford, CA 94305, USA \\ b Duke University, Nicholas School of Environment, Box 90227, Durham, NC 27708, USA \\ ${ }^{\mathrm{c}}$ Resources for the Future, 1616 P St, NW, Washington, DC 20036, USA \\ ${ }^{\mathrm{d}}$ National Bureau of Economic Research, 1050 Mass. Ave., Cambridge, MA 02138, USA
}

\section{A R T I C L E I N F O}

\section{Article history:}

Received 20 February 2007

Received in revised form 28 February 2008

Accepted 1 March 2008

Available online 8 March 2008

\section{JEL classification:}

Q21

Q28

Q48

$\mathrm{O} 38$

\section{Keywords:}

Exogenous

Technology

R\&D

Learning

Induced

\begin{abstract}
A B S T R A C T
The approach used to model technological change in a climate policy model is a critical determinant of its results in terms of the time path of $\mathrm{CO}_{2}$ prices and costs required to achieve various emission reduction goals. We provide an overview of the different approaches used in the literature, with an emphasis on recent developments regarding endogenous technological change, research and development, and learning. Detailed examination sheds light on the salient features of each approach, including strengths, limitations, and policy implications. Key issues include proper accounting for the opportunity costs of climaterelated knowledge generation, treatment of knowledge spillovers and appropriability, and the empirical basis for parameterizing technological relationships. No single approach appears to dominate on all these dimensions, and different approaches may be preferred depending on the purpose of the analysis, be it positive or normative.
\end{abstract}

(C) 2008 Elsevier B.V. All rights reserved.

\section{Introduction}

One of the most complex and salient questions remaining in climate change policy modeling is the appropriate treatment of technological change (TC). The approach to modeling TC is widely considered to be one of the most important determinants of the results of climate policy analyses; that is, the level of emissions abatement that can be achieved at a given cost. In this context, TC can be understood as the increase in outputs (including abatement) possible with a given level of inputs through the processes of invention, innovation, and diffusion. Unfortunately, the complex mechanisms by which these processes

\footnotetext{
* Corresponding author. Nicholas School of the Environment, Duke University, Box 90227, Durham, NC 27708, USA. Tel.: +1 919681 8865; fax: +1 9196845833.

E-mail addresses: kgilling@stanford.edu (K. Gillingham), richard.newell@duke.edu (R.G. Newell), pizer@rff.org (W.A. Pizer).
} 
work are not captured easily in modeling frameworks, creating significant difficulties for modelers attempting to determine the effects of climate policies that inevitably are intertwined with TC in energy supply and demand technologies.

In climate change policy models, endogenous technology change (ETC) implies incorporating a feedback mechanism by which policy changes the direction of TC toward carbon-saving technology change; ETC may also affect the overall rate of TC. This feedback occurs through channels such as energy prices, added specification of research and development (R\&D) activities, or accumulated production experience lowering production costs (learning-by-doing). This contrasts with exogenous assumptions about the rate of overall and carbon-saving TC, which are unresponsive to policy. This paper addresses several specific questions. What are the major assumptions regarding TC in climate policy models and, more specifically, how is TC made endogenous? What are the advantages and disadvantages of these approaches? And finally, what can we learn from these approaches?

The aim is to provide guidance to climate policy modelers looking to either incorporate ETC or refine existing ETC specification in their specific models. We find that although there is currently no single best means to endogenize TC, some methods appear better suited to certain model types than others. For example, approaches based on feedback through R\&D activities have been profitably developed in more highly aggregated forward-looking optimization models, such as dynamic computable general equilibrium models and some integrated assessment models. In contrast, learning-induced approaches have been most commonly used in disaggregated energy technology and system models. Table 1 summarizes the modeling of TC in a sample of climate change policy models and highlights the variety of approaches in different types of models.

The paper is organized around the common avenues of modeling TC, elucidating these approaches in the context of specific models and examining the implications and limitations of each. Instead of a comprehensive review of the ETC modeling literature, we restrict our review to select papers that illustrate

Table 1

Technological change characteristics in selected climate policy models

\begin{tabular}{llll}
\hline Model & Type & Representation of technological change & Reference \\
\hline SGM & CGE & EX & MacCracken et al. (1999) \\
GEM-E3 & CGE & EX & Capros et al. (1997) \\
PACE & CGE & EX & Böhringer (1998) \\
G-CUBED & CGE & EX & McKibbin and Wilcoxen (1993) \\
GREEN & CGE & EX & Burniaux et al. (1992) \\
GTEM & CGE & PR & Jakeman et al. (2004) \\
MIT-EPPA & CGE & EX/PR/LBD & Jacoby et al. (2003) \\
Sue Wing-EPPA & CGE & R\&D & Sue Wing (2001) \\
SMULDERS & CGE & R\&D & Smulders and de Nooij (2003) \\
GOULD-SCHNDR & CGE & R\&D & Goulder and Schneider (1999) \\
DGEM & CGE/ME & EX & Jorgenson and Wilcoxen (1993) \\
WARM & CGE/ME & R\&D & Carraro and Galeotti (1997) \\
E3ME & ME & R\&D & Barker and Köhler (1998) \\
PIZER & CGE/IAM & EX & Pizer (1999) \\
MACRO & CGE/IAM & EX & Manne and Richels (1992) \\
DICE/RICE & IAM & EX & Nordhaus (1994) \\
IMAGE & IAM & EX/PR & Alcamo et al. (1998) \\
ICAM3 & IAM & LBD/PR & Dowlatabadi (1998) \\
ETC-RICE & IAM & R\&D & Buonanno et al. (2003) \\
R\&DICE & IAM & R\&D & Nordhaus (2002) \\
NEMS & ES & EX/PR/LBD & EIA (2003) \\
MARKAL & ES & LBD & Barreto and Kypreos (1999) \\
MESSAGE & ES & LBD & Grübler and Messner (1998) \\
POLES & ES & LBD & Kouvaritakis et al. (2000) \\
GOULD-MATHAI & CF & LBD/R\&D & Goulder and Mathai (2000) \\
\hline ACInMS: & & & \\
\hline
\end{tabular}

Acronyms:

Models: CGE, computable general-equilibrium model; ME, macroeconometric model; IAM, integrated assessment model; ES, disaggregated energy technology and system model; CF, cost-function model.

Technological Change: EX (exogenous); PR (price-induced); LBD (learning-by-doing); R\&D (research and development). Source: Grubb et al. (2002); Loschel (2002); and authors. 
key concepts and provide insight into the theoretical basis for ETC modeling methodology. ${ }^{1}$ The paper is organized as follows. Section 2 discusses the fundamental differences between exogenous TC and ETC. Section 3 describes the simplest method of endogenizing TC: direct price-induced ETC. Section 4 examines R\&D-induced ETC and Section 5 addresses learning-induced ETC. Section 6 brings together our conclusions with a discussion of the implications of the choice of ETC modeling structure for climate change policymodeling results.

\section{Exogenous or endogenous technological change?}

Until recently, the most widespread method of treating TC in climate policy modeling was to consider it an exogenous variable-simply an autonomous function of time. The fundamental distinction between exogenous TC and ETC is that with exogenous TC production possibilities depend only on time, whereas with ETC, these possibilities can depend in a variety of ways on past, present, and/or future expected prices and policy. Thus, with ETC current technological possibilities for producing output with various combinations of capital, labor, and emission limits depend on past activities. In turn, there is a dependence of future technological possibilities on current actions. The remainder of this section provides an overview of how to conceptualize exogenous TC versus ETC in climate policy models.

\subsection{Exogenous technological change}

There are several different ways that climate policy modelers have incorporated TC even when it is only a function of time. The simplest approach to TC is to assume that a Hicks-neutral productivity gain governs the overall progress of the economy. However, this approach does not capture the potential for TC to proceed in an energy-saving (or energy-using) manner. An easy modification that reflects an energy-saving direction to productivity improvements-within either the economy as a whole, or an individual sector-is to include an autonomous energy-efficiency improvement (AEEI) parameter, which increases the energyefficiency of the economy by some exogenous amount each year. The use of an AEEI parameter is particularly common in more aggregated models (e.g., MacCracken et al., 1999; Nordhaus, 1994). In more disaggregated models, overall energy-saving progress can also be implemented by Hicks-neutral productivity gains in a more energy-efficient sector or technology, or by adding a new energy-efficient technology to the menu of available technologies at a given point in time. Autonomous energy-efficiency improvement has the primary advantage of simplicity and transparency, and in addition reduces the risk of model nonlinearities, multiple equilibria, and permits ready sensitivity analysis with different AEEI values. ${ }^{2}$

In a similar vein, the use of backstop technologies can also be thought of as a form of exogenous TC. Backstop technologies are typically carbon-free energy sources that may be already known, but are not yet commercialized widely. It often is assumed that such a backstop technology is available in a virtually unlimited supply at a constant, but relatively high, marginal cost. If the price of energy inclusive of carbon policy becomes high enough, the backstop technology will penetrate the market and prevent the price of energy from rising further. ${ }^{3}$ Modelers often assume that the cost of the backstop technology is decreasing with time at its own autonomous rate-effectively implying that if the backstop comes into effect, then technology is improving solely as a function of time. Some models have more than one backstop technology, such as the GREEN model (Burniaux et al., 1992). Examples that others have given of backstop technologies include advanced solar power, nuclear fusion, and possibly renewable transportation fuels and advanced fossil-fuel generation technologies such as shale oil (Loschel, 2002).

\footnotetext{
${ }^{1}$ For surveys of the literature and other overviews of modeling methodology, see Loschel (2002), Clarke and Weyant (2002), Grubb et al. (2002), Azar and Dowlatabadi (1999), Grübler et al. (1999), Goulder (2004), Weyant (2004), Vollebergh and Kemfert (2005), Edenhofer et al. (2006), Köhler et al. (2006), Popp (2006a,b), Sue Wing and Popp (2006), Sue Wing (2006); Weyant and Olavson (1999); and Edmonds et al. (2000).

${ }^{2}$ While models with exogenous TC cannot capture directly the responsiveness of technology to climate policies, they can employ sensitivity analysis to evaluate how modeling results would be influenced if the AEEI, Hicks neutral gains in a more energy efficient sector, or the timing of a new energy efficient technology, evolved differently under alternative policy scenarios.

${ }^{3}$ For this reason, some authors have referred to backstop technologies as "semi-endogenous" because when the backstop enters force is a function of the energy price, which is endogenous (Sue Wing, 2006).
} 
Finally, in some econometric models with flexible functional forms there may be multiple trends determining the overall level and direction of technological change. For example, Jorgenson and Wilcoxen (1993) include five parameters describing technological change-two describing the overall level $\left(\alpha_{t}\right.$ and $\beta_{t t}$ ) and three describing the direction (the vector $\boldsymbol{\beta}_{p t}$ or factor biases):

$$
\ln C_{t}=\alpha_{0}+\ln p_{t}^{\prime} \alpha_{p}+\alpha_{t} g(t)+0.5 \ln p_{t}^{\prime} \beta_{p p} \ln p_{t}+\ln p_{t}^{\prime} \beta_{p t} g(t)+0.5 \beta_{t t} g^{2}(t),
$$

where $C_{t}$ is unit cost, $p_{t}$ is a vector of input prices, $g(t)$ is a time trend, and the $\alpha$ s and $\beta$ s are parameters. Here, overall productivity growth is given by the negative derivative of this expression with respect to time, or

$$
-\frac{\partial \ln C_{t}}{\partial t}=-\left(\alpha_{t}+\ln p_{t}^{\prime} \beta_{p t}+\beta_{t t} g(t)\right) g^{\prime}(t) .
$$

The presence of prices in Eq. (2) leads some to view this as a model of price-induced TC. However, it is useful to note that the actual cost function (1) at a given point in time does not depend at all on historic prices or other variables-today's production possibilities depend on the passage of time only. Thus, even though the observed rate of TC appears endogenous, the underlying technology possibilities are not, so this formulation effectively represents a form of exogenous TC. Put another way, while the movement of the production frontier is purely exogenous, the summary "rate of technological change" depends on where along the frontier progress is measured and, therefore, is sensitive to prices.

\subsection{Endogenous technological change}

While modeling TC exogenously simplifies the modeling of TC, there is a wide literature acknowledging that TC is a complex process that is dependent on more than just the passage of time. This implies that the cost function (1), for example, depends not just on time and current prices, but also on historic indicators of prices and activity. Note that the vector of cost shares from Eq. (1), given by Sheperd's lemma, is $z_{t}=$ $\alpha_{p}+\beta_{p p} \ln p_{t}+\beta_{p t} g(t)$. An ETC version of this would replace the trend in cost shares (i.e., the direction or input-bias of technological change), $\beta_{p t} g(t)$, now governed only by the passage of time, with a more complex function of historic prices and/or economic activity. This view has motivated considerable work on the processes by which historic prices (and policies) influence today's production possibilities (e.g., see Oravetz and Dowlatabadi, 1995; Newell et al., 1999; Jaffe et al., 2003; Grubb et al., 2002; Azar and Dowlatabadi, 1999). ${ }^{4}$ In particular, some of these studies criticize the use of AEEI as neglecting the causes that affect the evolution of technologies, leading to distorted and inappropriate model results. ${ }^{5}$ Moreover, other studies, such as Oravetz and Dowlatabadi, emphasize that modeling TC using AEEI is not entirely consistent with empirical evidence.

Another variant is to summarize the influence of historic prices and activity in terms of an unobserved "knowledge stock" that governs overall level and direction (i.e., input-bias) of technological change. The difficulty lies in determining exactly how this stock accumulates and affects future energy use and emissions. Empirical evidence suggests that prices, $R \& D$, and learning through past experience all play some role in the accumulation of this stock, yet there is no single structural theory that addresses exactly how this occurs, and hence, how each influences future production possibilities. Recent empirical studies have been more successful in isolating the effect on future energy use and emissions of inputs to innovation such as R\&D (e.g., Fisher-Vanden et al., 2006, 2004), outputs from innovation such as patents (e.g., Popp, 2001), and direct price-induced accumulation of energy-saving knowledge (e.g., Sue Wing, 2008b). Viewed in the context of Jorgenson and Wilcoxen's (1993) expression for input-biased technological change, these studies offer a rich view of the potential dependence of $\beta_{p t} g(t)$ on past prices and activity.

An important element of incorporating ETC is whether one assumes the reference case behavior, in turn based on historic behavior, is roughly optimal. One line of reasoning is that TC represents a constraint that,

\footnotetext{
${ }^{4}$ This extensive literature of EETC includes an edited book (Grübler et al., 2002), and four special journal issues (Resource and Energy Economics, 2003, vol, 25; Energy Economics, 2004, vol. 26; Ecological Economics, 2005, vol. 54; and The Energy Journal, 2006).

${ }^{5}$ This is related to the Lucas (1976) critique in that AEEI is not a "deep" structural parameter and it is unlikely to remain stable as policymakers change their behavior.
} 
when relaxed, yields lower costs for reducing emissions. A number of studies find this result when ETC is coupled with the possibility that TC is undersupplied due to innovation market imperfections (Grubb et al., 2002). In contrast, other studies implicitly or explicitly assume that TC in the base case is (roughly) optimal; therefore, allowing it to change in response to policy changes might not affect mitigation costs very much if other relative prices do not change very much-an envelope theorem result. ${ }^{6}$ These implicit assumptions about the optimality of TC in the base case often confound comparisons of the implications of different approaches for endogenizing TC.

Finally, it is important to note that the development of alternatives to exogenous TC has also been driven in part by the demand from policymakers for normative ("what is better") analyses of climate change policies that appropriately model technological change. However, the line between positive ("what happens if") and normative analysis often is blurred in many studies that include ETC, despite the different requirements of each. This blurring arises, in part, because the literature indicates that important positive questions have yet to be answered unequivocally. Among these is the basic question of exactly what drives technological change and, therefore, what ETC ought to capture and why. Unfortunately, this blurring may have led to the premature use of ETC modeling efforts in statements about the likely cost and timing of $\mathrm{CO}_{2}$ mitigation efforts.

Although difficult to categorize neatly, the most commonly used approaches model ETC in one of three ways: direct price-induced, R\&D-induced, and learning-induced. Direct price-induced TC implies that changes in relative prices can spur innovation to reduce the use of the more expensive input (e.g., energy) in accordance with the Hicks-induced innovation hypothesis. R\&D-induced TC allows for R\&D investment to influence the rate and direction of technological change. It often involves an explicit knowledge capital stock. There is considerable diversity in R\&D-based approaches to modeling TC, which for the sake of convenience we categorize into neoclassical growth extensions and multi-sector general-equilibrium approaches. Model structure is the dominant factor in this further division, as different model structures tend to lend themselves to different R\&D-based endogenizing approaches. Finally, learning-induced TC allows for the unit cost of a particular technology to be a decreasing function of the experience with that technology. Learning-by-doing (LBD) is the most commonly employed method used in this approach, where the unit cost of a technology is typically modeled as a decreasing function of its cumulative output.

\section{Direct price-induced TC}

Direct price-induced TC is a relatively straightforward method of endogenizing TC with conceptual roots dating back to Hicks (1932), who suggested:

A change in the relative prices of the factors is itself a spur to invention and to inventions of a particular kind-directed at economizing the use of a factor which has become relatively expensive. (Hicks, 1932: 124-125)

Kennedy (1964) and Kamien and Schwartz (1968) build upon Hicks' induced-innovation hypothesis by developing the concept of the innovation-possibility frontier (IPF). The IPF, also known as the induced innovation function, can be thought of as a production function for producing new knowledge that improves the productivity of the different inputs. Thus, for any given isoquant of the IPF, there is a tradeoff between improving productivity of one input versus the others. In the context of Eq. (1) and the derived input cost shares, this highlights that a reduction in one input cost share (e.g., energy) implies increases in the others (e.g., capital and/or labor). This provides a mechanism for changes in relative prices to induce innovation more in the direction of a particular input.

The theory of induced innovation has a solid empirical foundation and is widely recognized as an important consideration in the understanding of TC (Ruttan, 2002). The empirical evidence has been bolstered further recently with studies such as Newell et al. (1999), who find that historical energy-price increases account for one-quarter to one-half of the observed improvements in energy efficiency for a sample of consumer durables from 1958 to 1993. Popp (2002) finds that patenting in energy-related fields

\footnotetext{
${ }^{6}$ Such results include Nordhaus (2002), Goulder and Schneider (1999), Goulder and Mathai (2000), Sue Wing (2003), and Smulders and de Nooij (2003).
} 
increases in response to increased energy prices. Popp (2005, 2006b) extracts some of the most important findings about the interaction between technological change and environmental policy from the empirical literature: innovation responds to incentives, innovation within a field experiences diminishing returns over time, exogenous TC does not capture the nature of TC, and the social return to environmental research is high. We will see these concepts in play in the climate models discussed in the subsequent sections.

In the context of climate policy modeling, if the price of energy rises, price-induced TC will lead to greater energy efficiency, often through a productivity parameter that is tied to historic prices (or whose change is tied to current prices) or through earlier diffusion of energy-efficient technologies. The exact pathway through which this occurs depends greatly on the model structure. There are only a few examples of direct price-induced TC used in climate policy models due to the somewhat ad hoc, reduced-form nature of specifying the relationship between price and TC. In particular, there is no accounting for the cost of achieving these changes. It is most common for models that use price-induced TC to use an AEEI parameter or a LBD approach as well, as will be discussed in more detail in section five.

Perhaps the most faithful representation of price-induced TC through the use of the IPF is Jakeman et al. (2004). Jakeman et al. assume a fixed amount of technological change in each region and time period, which is allocated across inputs to all industries according to the relative prices of the inputs. In this case, including price-induced TC reduces the cost of meeting carbon mitigation targets.

In the ICAM3 model, the expectation that the price of energy will rise induces TC, as does LBD (Dowlatabadi, 1998). In the U.S. Energy Information Administration's NEMS model, price-induced TC is included in several modules, including the residential and commercial modules, while LBD is included in others, such as the industrial and electricity modules. In the NEMS residential module, price-induced TC is included to allow for earlier diffusion of energy-efficient technologies if fuel prices increase significantly and remain high over a multi-year period. Specifically, this earlier diffusion is accomplished by shifting the date of introduction into the market by up to 10 years if there is a doubling of prices from the base-year price that holds for 3 years. The length of the shift is a function of the price in comparison to the base-year price. The NEMS commercial module has an analogous structure for the diffusion of advanced commercial equipment (EIA, 2003).

The empirical evidence suggests that the price-inducement form of TC does have merit as a partial explanation; higher energy prices clearly are associated with faster improvements in energy efficiency (Newell et al., 1999; Popp, 2002). However, the reduced-form approach largely has been passed over for the R\&D- or learning-induced TC methodologies. We now turn to those approaches in more detail.

\section{R\&D-induced TC}

$\mathrm{R} \& \mathrm{D}$-induced TC is one of the most common approaches used to endogenize TC, and a variety of models have been developed along these lines. R\&D-based TC has a long-running theoretical foundation beginning with the early work by Kennedy (1964), Kamien and Schwartz (1968), and Binswanger and Ruttan (1978) in developing the IPF and the theory behind induced TC. More recent work by Acemoglu (2002) addresses how the tradeoff between innovation in different directions inherent in the IPF results endogenously from a firm's dynamic optimization problem. Sue Wing (2006) further develops this theory in the context of climate change policy. In a parallel vein, the endogenous-growth literature (e.g., Lucas, 1988; Romer, 1990; Grossman and Helpman, 1994; Aghion and Howitt, 1998; Acemoglu, 1998 and Kily, 1999) suggests the importance of including a stock of "knowledge capital" when modeling economic growth.

In the broadest sense, the stock of knowledge captures all information, skills, ideas, and experience that determine production possibilities. It summarizes the influence of historic prices and activity on current production. In this way, flows into the knowledge stock can represent increasing educational attainment, increasing experience in production, and, most commonly, investments in R\&D which are determined by relative prices (Sue Wing, 2008a).

Climate policy modelers have introduced a knowledge stock in a variety of different ways. While the theoretical basis for relative prices inducing TC in a particular direction is quite well-developed, exactly how the knowledge stock accumulates and influences production possibilities is not completely settled in the literature. In some models, the concept of the knowledge stock is made more concrete by using an IPF to govern how investments in R\&D increase the knowledge stock. Popp (2004) develops one such model and discusses the use of empirical evidence to parameterize the IPF. This work, along with Popp $(2002,2003$, 
2006b), further informs our understanding of the innovation process. Model structures vary in terms of whether they permit embedding the IPF within a perpetual inventory framework for the knowledge stock, analogous to inventory methods for standard capital stocks.

We organize our discussion to first address approaches in recent theoretical R\&D models that may be useful to inform numerical models, and then delve into numerical models that include different representations of $R \& D$-induced TC. While several different representations may be possible in any given model, we arrange the discussion of numerical models based on model structure to highlight how different processes have been successful used in different model structures and what the implications of each are.

Several themes resonate throughout the R\&D model literature. Two key points are whether R\&Dinduced TC is associated with an innovation market imperfection due to spillovers, and whether carbonsaving R\&D crowds out R\&D in other sectors. A third point is whether there is a substitutability, as in most papers, or complementarity between the generation of output (i.e., conventional production) and the generation of new knowledge (i.e., innovation). These themes appear in many of the models addressed, and will be discussed in more detail in a summary and distinctions subsection at the end of this section.

\subsection{Theoretical models}

The endogenous growth literature gave rise to the concept of including a stock of knowledge capital in an economy-wide production function, a concept that has often been applied to endogenize TC in climate policy models. Of course, including a knowledge stock does not on its own imply a pathway for inducing carbon-saving TC. In the simple formulation of a knowledge stock that is most true to the endogenous growth literature, the knowledge stock increases the productivity of all inputs equally.

For example, Buonanno et al. (2003) extend the Nordhaus and Yang (1996) RICE model to implement such a knowledge stock in the ETC-RICE numerical model. Specifically, they use the following production function for each country:

$$
Y=A K_{\mathrm{R}}^{\beta}\left(L^{\gamma} K^{1-\gamma}\right)
$$

where $Y$ is economic output, $A$ allows for exogenous TC, $K_{\mathrm{R}}$ is knowledge capital, $L$ is labor, $K$ is physical capital, and $\beta$ and $\gamma$ are parameters. ${ }^{7}$ As in Nordhaus and Yang, the social planner chooses both the optimal level of standard investment and the investment in R\&D effort, where the cost of both types of investment is subtracted from the DICE model's output balance equation.

This simple methodology for endogenizing TC may be useful to capture important aggregate dynamics, but it leaves no pathway for relative prices to influence energy-saving or carbon-saving innovation. ${ }^{8}$ Many numerical models include a factor-augmenting knowledge stock to represent such a pathway. Sue Wing (2003) provides one such example, which is discussed in detail under numerical models. But first, we will discuss two recent theoretical approaches that model endogenous growth by changes in a continuum of intermediate goods. These approaches provide some insight for numerical models and may help guide future numerical modeling.

Smulders and de Nooij (2003) and van Zon and Yetkiner (2003) both build on the endogenous growth literature that includes a continuum of intermediate goods (e.g., Romer, 1990) and apply a variation of this modeling approach to an economy that includes energy as an input to production. In Smulders and de Nooij, endogenous TC is achieved by improvements in the quality of the continuum of intermediate goods through investment in R\&D, while van Zon and Yetkiner achieve endogenous TC through increases in the variety of the continuum of intermediate goods through R\&D investment. Both papers demonstrate the important theoretical point that profit maximization by innovating intermediate goods producers can give rise to a change in the direction of TC toward energy-saving TC based on increasing energy prices or constrained energy quantities.

\footnotetext{
${ }^{7}$ If the elasticity of knowledge $\beta$ is positive, this specification results in increasing returns to scale; if $\beta-\gamma$ is positive (i.e., $\beta+1-\gamma>1$ ), it results in increasing returns to scale in non-fixed inputs. Increasing returns to scale in non-fixed inputs can lead to an unbounded control problem and the absence of a competitive equilibrium.

${ }^{8}$ Buonanno et al. include another pathway for relative prices to influence innovation, as will be discussed in the section on numerical models.
} 
We present the structure of the Smulders and de Nooij model to provide insight into the process of endogenous TC used. The van Zon and Yetkiner model is closer to Romer (1990) in its use of discrete "blueprints" to achieve variety of the continuum of intermediate goods-but the underlying process of endogenizing TC is similar.

Smulders and de Nooij begin by including a factor-augmenting knowledge stock, where final output $(Y)$ is modeled as a constant elasticity of substitution (CES) production function of augmented labor $(L)$ and augmented energy resources $(E)$ :

$$
Y=A \cdot \Phi\left(A_{L} L, A_{E} E\right),
$$

where $A$ is exogenous Hicks-neutral TC. $A_{L}$ and $A_{E}$ are endogenous factor augmentation technology levels for labor and energy services respectively. They are defined for $i=L, E$ as

$$
A_{i}=\int_{0}^{1} q_{i k}\left(\frac{x_{i k}}{S_{i}}\right)^{1-\beta} \mathrm{d} k
$$

where $q_{i k}$ is the quality level of intermediate goods of type $k$ (for capital), $x_{i k}$ is the use of intermediate goods of type $k$ for the production of type $i$ services, $S_{i}$ is the use of raw input $i$. The number of intermediate goods in each sector is normalized to unity. The market for intermediate goods is characterized by monopolistic competition.

ETC is modeled in this framework by assuming that each intermediate goods producer improves the quality of the good by investing in R\&D. The rate of change in the quality of the good is given by

$$
\dot{q}_{i k}=\left[\xi Q_{i} D_{i}^{1-\omega_{i}}\right] D_{i k}^{\omega_{i}},
$$

where $D_{i k}$ is the flow of resources spent on R\&D by the firm, $D_{i}$ is the flow of sector-wide investment for input $i, \xi$ is a scaling parameter, $\omega_{i}$ is the share of innovation returns for intermediate good $k$ to input $i$ that accrue to the inventing firm (an appropriability parameter), and $Q_{i}$ is the current aggregate quality level (a proxy for a knowledge stock or level of technology). $Q_{i}$ is given simply as follows (for $i=L, E$ )

$$
Q_{i}=\int_{0}^{1} q_{i k} \mathrm{~d} k
$$

Each intermediate goods producer chooses $D_{i k}$ to maximize the net present value of the firm. Given this specification, there are two innovation spillovers. The first is that each individual firm builds on the knowledge accumulated by all firms in the sector, as given by $Q_{i}$. The second is due to $\omega$ representing the share of returns to innovation that are not appropriated, implying that quality development efforts are more productive when other firms in the sector are more active. In other words, each firm ignores how his or her investment benefits both other firms now (through the aggregate investment term $D_{i}$ ) and other firms in the future (through the accumulated stock term $Q_{i}$ ). Thus, two innovation market imperfections are modeled in this specification.

Smulders and de Nooij's modeling framework allows for policy analysis examining the short- and longrun growth implications of energy conservation policies but does not address questions of economic welfare. They find that energy-conservation policy will lead to reduced net per capita income levels due to the direct costs of the policy outweighing the offsetting effect of induced innovation. Nonetheless, the ETC framework does reduce the cost of a policy, although non-energy R\&D activities may be crowded out, with no increase in total R\&D. In fact, a theoretical result based on this model structure is that the gains from induced innovation will never offset the initial policy-induced decline in per capita income levels, obviating the possibility of "win-win situations." ${ }^{9}$ As a general proposition, ETC should induce higher long-run output only if spillovers are relatively high in carbon-saving innovation compared to other areas that would otherwise receive R\&D effort. This appears not to be the case in Smulders and de Nooij's model.

In contrast, van Zon and Yetkiner use a blueprint framework to find that an energy tax that is recycled in the form of an R\&D subsidy may increase long-run growth, through R\&D-induced TC. This result stems from

\footnotetext{
9 This result does not hold in other model frameworks (e.g., Fischer and Newell (2008)).
} 
two different market imperfections in the R\&D market: (1) firms do not consider the effect that current R\&D has on increasing the productivity of future R\&D investment because it is not captured appropriately in the price of the blueprints and (2) a market imperfection in the supply of intermediates that leads to too low of a demand for those intermediates relative to the social optimum. Effectively, these market imperfections imply an intertemporal spillover for each firm, rather than a spillover from the research of one firm to other firms. Crowding out also plays a less prominent role in the van Zon and Yetkiner model than in Smulders and de Nooij.

\subsection{Numerical models}

Unfortunately, theoretical models with continuous intermediate goods and abstract representations of blueprints are not well-suited to match up to measurable real-world variables or technologies that most numerical models attempt to represent. However, the more general notion of including a Hicks-neutral knowledge stock, as shown above in Buonanno et al. (2003) or factor-augmenting knowledge stock, as in Smulders and de Nooij (2003), is a common choice for numerical models that include an economy-wide production function. Popp $(2004,2006$ a) provides a good example of this approach in an economy-wide production function. However, recent models have also used a knowledge stock to determine the greenhouse gas intensity ratio, in an economy-wide abatement cost function, and in multi-sector general equilibrium models. The modeling of spillovers and crowding out continue to play a crucial role in determining the implications of the different processes for endogenizing TC.

\subsubsection{Knowledge in greenhouse gas-intensity ratios}

In the original Nordhaus (1994) DICE model, carbon intensity is affected by the substitution of capital and labor for carbon energy. This is modified in the R\&DICE model in Nordhaus (2002), so that carbon intensity is determined by an IPF, which takes the form:

$$
\dot{\sigma}_{t} / \sigma_{t}=\Psi_{1} R_{t}^{\Psi_{2}}-\Psi_{3}
$$

where $\sigma_{t}$ is the industrial carbon energy/output ratio at year $t$ (implying $\dot{\sigma_{\mathrm{t}}} / \sigma_{\mathrm{t}}$ is the rate of change of the carbon energy-output ratio), $R_{t}$ is the R\&D inputs into the carbon-energy sector in year $t$, and the $\Psi_{i}$ are parameters (calibrated assuming optimized R\&D in the past). Emissions in R\&DICE are a function of the exogenously determined output and the endogenous carbon-output ratio $\sigma_{t}$.

The cost of investing in knowledge through R\&D is subtracted from consumption in the DICE model's output balance equation, analogous to conventional investment. In the case of R\&D investment, however, the cost of research is multiplied by four to reflect a generic innovation market imperfection; that is, that the social opportunity cost of R\&D exceeds its private cost due to crowding out. By implication, in equilibrium the rate of return to carbon energy $R \& D$ also exceeds the return to ordinary standard investment by a factor of four in the base case.

Nordhaus (2002) compares this ETC specification with the specification in DICE (where carbon intensity only is affected by mitigation efforts substituting abatement for consumption). His primary conclusion is that induced innovation is likely to be less powerful of a factor in reducing emissions than substitution. This result is related directly to the calibration that assumes the returns to R\&D equal the opportunity costs, allowing crowding out to have an important effect.

Returning to the ETC-RICE model, Buonanno et al. (2003) provide a different variation on Nordhaus' approach by making emission intensity a function of the knowledge stock $K_{\mathrm{R}}$ also used in Eq. (3). They term this "induced TC" and their formulation is

$$
\frac{E}{Y}=\left[\sigma+\chi e^{-\alpha K_{\mathrm{R}}}\right](1-\mu),
$$

where $E$ is emissions, $Y$ is output, $\alpha$ is the elasticity by which knowledge reduces the $E / Y$ ratio, $\sigma$ is an exogenous parameter describing the value to which the $E / Y$ ratio tends to asymptotically as the stock of knowledge increases, $\chi$ is a scaling coefficient, and $\mu$ is the rate of abatement effort. A positive value for the scaling coefficient $\chi$ indicates that R\&D efforts will result in emissions-saving TC. The knowledge stock accumulates one-to-one with $R \& D$ investment and depreciates at an exogenous rate. Importantly, there is 
no potential for climate-friendly R\&D to compete with or crowd out other, aggregate R\&D-this knowledge stock is exactly the same variable that influences overall productivity.

Buonanno et al. also incorporate ETC in third way, where they allow for spillovers from an international knowledge stock of R\&D to other regions' productivity (modeled by an additional spillover term of $K_{w}^{\varepsilon}$, equal to the sum of knowledge in other regions, multiplied by the left-hand side in Eq. (3)).

An interesting result is that the total cost of achieving Kyoto targets rises when "induced TC" is modeled versus "endogenous TC" (Eq. (3)) only and rises again when international spillovers are added. This result seems surprising since we tend to expect that additional avenues (such as domestic or foreign $R \& D$ ) to mitigate could only lower costs, and so presumably arises from their calibration. In particular, when they insert the induced technological change specification, it does not necessarily match the endogenous TConly run with knowledge held fixed-the parameters are based on an OLS fit. Similarly, the production parameters are changed when international spillovers are included. In the latter case, a parameterization that-other things equal-meant less appropriability would, in fact, decrease R\&D.

\subsubsection{Knowledge in abatement cost functions}

Some model structures are based on an economy-wide carbon-abatement cost function, rather than on a production function. While an abatement cost function can be derived from the production function approach, directly modeling the abatement cost function lends itself to slightly different approaches to ETC.

Goulder and Mathai (2000) create a set of optimizing equilibrium models with knowledge accumulation that directly reduces abatement costs. One set of models uses a cost-effectiveness criterion and solves for the time path of abatement and R\&D investment to minimize the present value abatement costs of achieving a concentration target under different TC assumptions. The second set of models uses a costbenefit criterion and solves for the time path of abatement and R\&D investment that minimizes present value social costs (including climate damages) under different TC assumptions.

Into each of these frameworks, they separately incorporate both R\&D and LBD, which govern the rate of knowledge accumulation; the LBD specification will be discussed in Section 5. All innovation market imperfections are assumed to have been corrected already by public policy, so there is no appropriability problem in the model.

In the cost-effectiveness R\&D-based model, the social planner's objective function covers each time period $t$ from the present into the infinite future, as follows

$$
\min _{a_{t}, R_{t}} \int_{0}^{\infty}\left(C\left(a_{t}, H_{t}\right)+p\left(R_{t}\right) R_{t}\right) e^{-r t} \mathrm{~d} t,
$$

where $C(\cdot)$ is the cost function, $a_{t}$ is the level of abatement at time $t, H_{t}$ is the stock of knowledge, $p(\cdot)$ is the real price of investment resources, and $R_{t}$ is investment in knowledge (i.e., R\&D expenditure). This minimization problem is subject to a constraint governing the change in the concentration of $\mathrm{CO}_{2}$ in the atmosphere (the concentration target), as well as a constraint governing the change in the knowledge stock.

In this second constraint, the accumulation of knowledge $\left(H_{t}\right)$ is given by

$$
\dot{H}_{t}=\alpha_{t} H_{t}+\Psi\left(R_{t}, H_{t}\right),
$$

where $\alpha$ is the rate of autonomous TC (an AEEI term), and $\Psi$ is the knowledge accumulation function. The initial knowledge stock $\left(H_{0}\right)$ is initialized to unity. Goulder and Mathai also assume that the knowledge accumulation function $\Psi$ has the following properties: $\Psi(\cdot)>0, \Psi_{R}(\cdot)>0$, and $\Psi_{H}(\cdot)<0$.

In this formulation, R\&D investment increases the knowledge stock and thereby reduces future abatement costs. On the other hand, R\&D investment also adds to the costs that the social planner is attempting to minimize. A key theoretical result out of the cost-effectiveness framework is that the presence of R\&D-induced TC implies a reduction in near-term abatement and an increase in later abatement (i.e., a "steeper" optimal time path of abatement), a result that contrasts with claims (typically driven by assumptions about learning, discussed later) that endogenizing TC should lead to more aggressive near-term action. Under both frameworks, Goulder and Mathai also find that including R\&D in their model formulation lowers the time path of the carbon tax, since the carbon tax is relatively more effective in reducing emissions with ETC than without. At the same time, in the cost-benefit framework this implies a higher overall optimal level of abatement, since emissions reductions relatively are less 
expensive. Similarly, it implies higher overall welfare for society (i.e., lower overall costs, including climate damages).

\subsubsection{Knowledge in multi-sector general equilibrium approaches}

Multi-sector general equilibrium models differ from the previous approaches in that the economy is disaggregated into distinct sectors and the economic activity within and between sectors is modeled. The strength of the approach is that it may provide additional insights on the effects of interactions between sectors, such as spillovers-or crowding out-from R\&D. The cost is that general equilibrium models tend to be data intensive and computationally demanding. We focus here on approaches that include explicit ETC. $^{10}$

Just as in several of the models discussed above, some general equilibrium models explicitly endogenize TC through the inclusion of knowledge capital in the production function, albeit at a sectoral level, rather than economy-wide. One notable example is Goulder and Schneider (1999). Goulder and Schneider develop a partial equilibrium analytical framework and then implement some of the resulting insights in a numerical general equilibrium model that endogenizes TC, with a particular emphasis on spillover effects.

Specifically, in their general equilibrium model, Goulder and Schneider divide the knowledge stock into appropriable knowledge $(H)$ and non-excludable knowledge $(\bar{H})$. The non-excludable knowledge represents the spillover knowledge enjoyed by all firms in each industry (but not across industries). A scaling factor, $\gamma(\bar{H})$, is then used to determine the effect of $\bar{H}$ on output in the CES production function for a representative firm in each industry:

$$
Y=\gamma(\bar{H})\left(\alpha_{H} H^{\rho}+\alpha_{G} G^{\rho}\right)^{1 / \rho},
$$

where $Y$ is output, $G$ is an aggregate of all other production inputs (labor, ordinary capital, and several intermediate inputs), and the $\alpha \mathrm{s}$ and $\rho$ are parameters. There are four intermediate goods industries (conventional energy, alternative energy, energy-intensive materials, and other materials), and three industries that produce final goods or services (new physical capital investment, R\&D service goods, and general consumption goods). The scaling factor $\gamma(\bar{H})$ is an increasing function of non-excludable knowledge that levels off to a constant in the long run in order to allow for steady-state growth. Note that this production function implies that for each representative firm, R\&D will influence output both through the firm's input of appropriable knowledge and the spillovers from non-excludable knowledge generated in the industry.

In particular, Goulder and Schneider assume that appropriable knowledge capital accumulates linearly with R\&D expenditure:

$$
H_{t+1}=H_{t}+\varepsilon R_{t},
$$

where $R_{t}$ is the real expenditure on $R \& D$ at time $t,{ }^{11}$ and $\varepsilon$ is a constant governing the rate at which R\&D services increase the appropriable knowledge stock. Note that this specification implies that appropriable knowledge capital does not depreciate (a departure from how the physical capital stock is treated). Goulder and Schneider find that the qualitative results do not depend greatly on the specification in Eq. (13) but rather depend on the initial differences across industries in the marginal social returns to R\&D due to asymmetries in both spillovers and the tax treatment of R\&D.

Spillovers derived from the production of non-excludable knowledge $\bar{H}$ are a critical component driving the model results, as can be seen by the scaling factor $\gamma(\bar{H})$ in the firm's production function in Eq. (12). Non-excludable knowledge is assumed to accumulate in the same manner as appropriable knowledge

$$
\bar{H}_{t+1}=\bar{H}_{t}+\beta \bar{R}_{t},
$$

\footnotetext{
10 This is in contrast to macroeconometric approaches, such as Carraro and Galeotti (1997). Carraro and Galeotti decompose capital into "energy-saving" or "energy consuming" stocks, with the idea that policies affect the incentives of firms to invest in R\&D in each of these types of capital. Carraro and Galeotti infer technical progress econometrically by examining the dynamics of other variables. Specifically, a latent variable structural equation is used to extract information about TC without having an exact representation of TC.

11 Goulder and Schneider (1999) assume a single representative firm for each industry, so $R_{t}$ is also the industry-wide expenditure on R\&D at time $t$.
} 
where $\bar{R}_{t}$ is the industry-wide expenditure on R\&D at time $t\left(\bar{R}_{t}=R_{t}\right.$ due to the single representative firm), and $\beta$ is a parameter governing the magnitude of potential spillovers $(\beta=0$ represents the case of no spillovers). Firms are assumed to have perfect foresight and make investment decisions in physical capital and R\&D to maximize the present value of the firm. Model runs are made with different assumptions about pre-existing distortions in the R\&D market, which depend on the array and magnitude of knowledge spillovers (e.g., value of $\beta$ in different industries), as well as the industrial allocation and scope of prior subsidies to R\&D. Goulder and Schneider apply the model to assess the consequences of carbon tax and R\&D subsidy policies with and without these prior distortions.

Goulder and Schneider find that the presence of ETC in their model leads to lower costs of achieving a given abatement target, but higher gross costs of a given carbon tax (i.e., costs before netting out climate benefits). In fact, both costs and benefits of a given carbon tax are higher relative to their model with only exogenous TC (where $H$ is exogenous and $\beta=0$ ), due to more extensive carbon abatement, for the economy responds more elastically to price shocks from the policy. With environmental benefits included, Goulder and Schneider find greater net benefits of this higher abatement level for a given carbon tax when ETC is present. This outcome can be reinforced or muted if there are prior distortions in R\&D markets, depending on the type of distortions.

One important feature underlying these results is a crowding out effect where expansion of knowledge generation in one sector comes at a cost to other sectors due to the limited pool of knowledge-generating resources (i.e., there is a positive and increasing opportunity cost to R\&D in one sector). A carbon-tax policy serves to spur $R \& D$ in the alternative energy sector, but discourages $R \& D$ in non-energy and conventional energy sectors due both to slower growth of output in those industries and the limited pool of knowledgegenerating resources. ${ }^{12}$

On the other hand, the knowledge spillover effects, whereby policy-induced R\&D has social returns above private returns, provide additional benefits from a climate policy above the environmental benefits. However, the presence of ETC with spillovers does not imply the possibility of zero-cost carbon abatement, unless the spillovers overwhelm the crowding out effect, a largely empirical question. In a separate model run, Goulder and Schneider find that private R\&D subsidies only play a role when TC is endogenous, and their effect is found to be contingent on the size of the knowledge spillovers (the $\beta$ parameter), as one would expect.

Sue Wing (2003) incorporates ETC into a detailed general equilibrium model, building on several of the concepts in Goulder and Schneider (1999) and some of the other papers discussed above. At the core of Sue Wing's model is a recursive, dynamic general equilibrium model in which a representative agent maximizes welfare. Producing industries maximize profits subject to the technologies of production and consumption, the economy's endowments of primary factors and natural resources, and existing taxes and distortions. The agent leases the services of the endowed factors of production to the industries to produce commodities, which provides the income used to pay for consumption, investment, and R\&D.

A major difference between Sue Wing's model and previous models is that Sue Wing further distinguishes several of the factors influencing innovation to gain insight into the general equilibrium effects of inducing innovation in one sector and its consequences for the cost of carbon policies. Conceptually, Sue Wing describes his approach in terms of two commodities: a "clean" commodity and a "dirty" commodity. There is one industry for each, and both commodities are used as input to production. Each industry $i$ has a production function at time $t$ given by

$$
Y_{i}(t)=\phi\left[v_{i}(t), y_{i}(t)\right]
$$

where $Y_{i}(t)$ is each industry's output after adjustment for knowledge services, $\varphi$ is a nested CES function, $v_{i}$ $(t)$ reflects "intangible knowledge services," and $y_{t i}$ is each industry's nested CES production function (in terms of intermediate goods and other factors of production). Technical change is the effect of $v_{i}(t)$ on each industry's production function (shifting the envelope of possibilities for substituting clean inputs for dirty

\footnotetext{
12 Goulder and Schneider (1999) model the entire pool of knowledge-generating resources as inelastic, but in the long run it may be more elastic, for example through increases in the pool of R\&D labor.
} 
inputs). Intangible knowledge services allocated to each industry, $v_{i}(t)$, are modeled as a function of the rate of return to $R \& D$ investment (also a function of the prices of output in a given sector), as follows

$$
v_{i}(t)=\vartheta\left(p_{i}(t), \bar{H}(t)\right)
$$

where $p_{i}(t)$ is the price of output from each industry, and $\bar{H}(t)$ is the aggregate knowledge stock over all industries. The function $\vartheta$ is assumed to be increasing with both prices and the knowledge stock. This formulation allows for the inter-sectoral distribution of knowledge services to be shifted by changing relative prices, even if the stock of knowledge remains constant. The aggregate knowledge stock accumulates over time as a function of economy-wide R\&D investment:

$$
\dot{\bar{H}}(t)=\varpi(\bar{R}(t), \bar{H}(t))
$$

where $\bar{R}(t)$ is the economy-wide R\&D investment. The function $\varpi$ is assumed to be increasing with $\bar{R}(t)$ and decreasing with $\bar{H}(t)$, implying diminishing returns to knowledge. Finally, R\&D investment is determined by a fixed marginal propensity to save and the relative cost of tangible and intangible investment.

Using this formulation of ETC within a numerical general equilibrium model, Sue Wing (2003) finds that a carbon tax reduces aggregate $R \& D$, slowing the rate of TC and the growth in output. Given the fixed-saving rule and absence of knowledge spillovers, this follows from having a smaller economy due to the carbon tax. However, the relative price effects of a carbon tax lead to considerable reallocation of knowledge services, enabling the economy to adjust to the carbon tax in a more elastic manner, reducing the total costs of the carbon tax. Sue Wing finds that this effect of ETC is substantial due to shifting of knowledge services.

\subsection{Summary and distinctions}

This overview of approaches to modeling R\&D-induced TC, while by no means comprehensive, captures the pathways through which TC has been endogenized as a function of R\&D. Other recent studies with explicit R\&D-induced TC include Bollen et al. (2004), Schneider and Goulder (1997), and Grubb et al. (1995).

Given the great diversity of model structures with R\&D-induced TC, some important distinctions are warranted to clarify the approaches and explain certain implications of the modeling methodologies. First, it is important whether R\&D activity is assumed to be optimal in the calibrated base case or whether it is subject to distortions. The models above differ in whether there are prior distortions in the R\&D market, what type of distortions these are, and the potential for policy interventions to partially correct or exacerbate the distortions with corresponding welfare benefits and costs.

It also can be important whether there is a substitution or complementarity between the generation of output and knowledge, as is shown most clearly in Buonanno et al. (2003). Nearly all of the other studies in question have some mechanism where the generation of output substitutes for the generation of knowledge, implying a larger role for crowding out and less opportunity for gains from ETC. Buonanno et al., with an emphasis on complementarity between energy-saving R\&D and aggregate productivity R\&D (they use the same knowledge), embed more opportunity for increased energy-saving R\&D to at the same time boost overall productivity.

Related to this issue is the important difference among models in the elasticity of the supply, or opportunity cost, of additional R\&D. If there is a relatively inelastic supply of $R \& D$ (e.g., capable engineers and scientists), more effort on climate mitigation R\&D reduces the ability of other firms or sectors to perform R\&D, effectively crowding out R\&D activity. This R\&D crowding out behavior is evident in several models, where a subsidy or tax policy that induces energy-saving R\&D will decrease R\&D in other sectors of the economy, potentially decreasing aggregate economic output (e.g., Nordhaus, 2002; Goulder and Schneider, 1999; Sue Wing, 2003). This implies that the cost of a carbon constraint could be more or less costly with the inclusion of ETC (versus presumptively leading to lower costs).

In addition to crowding out, there are spillover effects, or the degree to which R\&D by any specific sector or firm is appropriable (Clarke and Weyant, 2002). In other words, it is the degree to which firms, in equilibrium, fail to capture the full benefits of their R\&D investment outside of the firm. This divergence between private and social returns to R\&D can imply a relatively high social return to R\&D. If a firm can successfully appropriate most of the gains from R\&D expenditure, it will have more incentive to undertake 
$R \& D$ and the social returns of that R\&D will converge with the private returns. On the other hand, if firms appropriate less of the profits of their R\&D, they will be less likely to undertake R\&D and the R\&D they do undertake will have high social returns due to unappropriated spillover effects.

With significant spillovers, we have a preexisting market imperfection (i.e., social returns above private returns) that may be partially corrected by an emissions policy and more directly corrected by an R\&D policy. Spillovers have been used in various ways in the papers described above, but in nearly all cases, more spillovers tend to imply a lower cost of achieving a given carbon constraint due to a partial correction of the R\&D market imperfection.

There clearly exists a tension between spillovers and crowding out, with the former pointing to greater cost savings when ETC is included and the latter dampening or even overturning that effect. In many models, the degree to which spillovers and crowding out arise is a complex interaction among underlying assumptions about model structure and distortions in the R\&D market. Yet, these assumptions have important ramifications for the total cost of a climate policy as well as the conclusions drawn about the degree to which previous estimates based on exogenous technology assumptions are biased.

Whether models are couched in terms of spillovers or appropriability, it is important to keep in mind that R\&D market imperfections generally are hard to correct. A recent paper by Otto et al. (2006) points out that while a climate policy focused in part on technological change can have lower costs than one only focused on mitigation, a policy that solved the general R\&D market imperfection would provide large benefits. However, such policies are hard to come by in practice.

Regardless, the relative price of energy clearly has a role in influencing the direction of TC even if effects on the overall level of R\&D are limited, and even if the effect on costs is ambiguous. ${ }^{13}$ Higher prices of inputs to production create an incentive to improve technology to economize on the use of such inputs. In the case of energy, this would imply that a carbon policy encourages R\&D investment directed at lowering the costs of such a policy. For example, Sue Wing (2003) hypothesizes that relative prices affect how the "knowledge services" from the knowledge capital are allocated throughout the economy. This concept of ETC has strong implications for the way innovation is reallocated under a carbon policy as firms attempt to reduce policy costs.

\section{Learning-induced TC}

Learning-induced TC approaches tend to be quite different than R\&D-induced approaches. In this section, the history and concepts behind learning will be discussed first, followed by a discussion of some approaches.

A long-recognized concept, technological learning first was quantified by Wright (1936) for the aircraft industry. He noted that unit labor costs in airframe manufacturing declined with accumulated experience, as measured by cumulative output. In economics, the concept is often described as learning-by-doing (LBD), and generally is defined as the decrease in costs to manufacturers as a function of cumulative output, or "learning-by-using," and the decrease in costs (and/or increase in benefits) to consumers as a function of the use of a technology (Arrow, 1962; Rosenberg, 1982). ${ }^{14}$ LBD commonly is measured in the form of "learning" or "experience" curves in terms of how much unit costs decline as a function of experience or production. Frequently, such curves are estimated in log-log form.

Historically, learning curves have been observed in many industries and are a well-established empirical concept (Azar and Dowlatabadi, 1999; Grübler et al., 1999; Loschel, 2002). They implicitly take into account in a reduced form all the parameters that influence the total costs of a product as it moves through the development stages toward becoming a mature technology. These parameters include those that govern production improvements, product development, and decreases in process input costs (Neij, 1997). Learning curves have the advantage of employing an empirically quantifiable concept to allow current prices and activity to influence future technology possibilities in a relatively straightforward manner.

Learning by its very nature is a self-reinforcing process: the more experience that is accumulated with one technology, the lower its cost and the more competitive the technology is, leading to even more

\footnotetext{
${ }^{13}$ It potentially also could boost the rate of productivity growth (e.g., Jorgenson and Wilcoxen 1993), but absent a market imperfection in the model (whether explicit or implicit), this should not increase welfare.

${ }^{14}$ Note that "learning-by-searching" (based on cumulative R\&D expenditures) also has been used in the literature, but it is essentially R\&D-induced TC (see, e.g., Bahn and Kypreos (2003)).
} 
accumulated experience relative to other choices. In this manner, including learning curves in models can induce path dependencies that could lead to "lock-in" of a particular technology pathway (Clarke and Weyant, 2002). This self-reinforcing process has been described as a "virtuous cycle" when applied to carbon-saving technologies (Grubb, 1997).

The primary disadvantage to learning-induced TC is its reduced-form nature. LBD can be inserted mechanically into many models, but it is difficult to identify the mechanisms behind LBD-or even be confident about the causality. Learning-induced TC does not have a theoretical structure analogous to the IPF on which R\&D-induced TC is based. The ease with which learning curves can be estimated may give a false sense of comfort and precision that may belie the R\&D or other resources that went into the technology development (Clarke and Weyant, 2002). For instance, it may be that the part of the underlying force driving learning curves is R\&D, through the following scenario: when production costs drop, the potential competitiveness of the product increases, increasing the rate of return on additional R\&D, inducing more $R \& D$, which lowers the costs further and at the same time spurs more production. In this case, there are unaccounted for R\&D costs that a reduced-form LBD approach does not capture. There is the further issue of reduced learning in technologies that experience lower production due to policy (e.g., certain fossil fuel technologies); this lost learning represents an opportunity cost.

Sue Wing (2001) expresses two additional reservations about learning-induced TC. First, he finds a lack of empirical data on the relative rates of learning in several advanced energy technologies, making model parameterization difficult. Second, he sees a disregard for the general equilibrium effects of learninginduced productivity improvements that may influence final results in models that include learning. For instance, if there is LBD in carbon-free energy technologies, lower costs will lead to increased demand and a shift from carbon-intensive energy technologies. This would tend to lower the demand for carbonintensive energy technologies, lowering their price (if supply is upward sloping) and changing the relative price ratio between carbon-free and carbon-intensive energy so that it is less favorable than it once was. This would serve to slow the market penetration of carbon-free energy technologies.

\subsection{Specific approaches}

Despite its disadvantages, the tractability of learning curves has led to the use of learning-induced TC throughout the literature, particularly in disaggregated "bottom-up" models. Disaggregated models are well-suited for incorporating learning because of their rich technology specificity, which easily lends itself to a learning curve for each technology. Some more aggregated models also use learning, but it is not as common. One reason is that learning tends to be thought of as a technology-specific phenomenon and therefore is harder to apply in the typical aggregation of a "top-down" model.

The most common way to capture learning-induced TC in climate policy models is based on an exponential relation between unit cost and cumulative output:

$$
C\left(K_{\mathrm{I}}\right)=\alpha K_{I}^{-\beta},
$$

where $C$ is the unit cost of a technology, $K_{\mathrm{I}}$ is the cumulative installed capacity (or cumulative output), $\alpha$ is the cost of the first unit (a normalization parameter), and $\beta$ is the learning elasticity. This implies that a doubling of experience will reduce specific costs by a factor of $2^{-\beta}$, also known as the progress rate. This formulation only requires the output and cost history to parameterize the learning function. However, the non-convexity of the problem solution has been an algorithmic hurdle to incorporating this learning function in many optimization frameworks (Grübler and Messner, 1998). Manne and Barreto (2004) explore some of these issues and suggest potential solutions.

A common result of including ETC through LBD is that the carbon tax needed to attain a specific $\mathrm{CO}_{2}$ concentration target tends to be lower than in models without LBD or with LBD turned off. This result is intuitive-with LBD modeled as described above, no R\&D expenditure is needed and any additional capacity of carbon-free energy technologies will lower the costs of that technology in the future, leading to more emissions reductions per dollar of further investment.

Another commonly observed result of incorporating LBD in climate policy models is that the optimal abatement path to reach a given concentration target involves increased near-term abatement and less abatement later (Grübler and Messner, 1998). This result occurs because increased near-term 
abatement encourages earlier LBD in low-carbon technologies, which lowers the long-term costs of abatement. $^{15}$

Other studies suggest that there are actually two factors. On one hand, there is the added value to nearterm technology investment due to LBD, as just mentioned. On the other hand, LBD also leads to lower costs of future abatement, which implies that abatement should be delayed. The net result of the two opposing effects may be theoretically ambiguous, but numerical simulations by Manne and Richels (2004) suggest that the slope of the optimal abatement curve over time actually may be steeper with LBD included, contrary to previous findings, such as those of Grübler and Messner (1998) described above. Goulder and Mathai (2000) also find an ambiguous result, with only a weak effect of LBD on the optimal abatement path.

To model LBD, Goulder and Mathai (2000) adjust their formulation of knowledge accumulation given above in Eq. (15), by replacing the R\&D investment $(R)$ with the level of abatement $(a)$ :

$$
\dot{H}_{t}=\alpha H_{t}+\Psi\left(a_{t}, H_{t}\right),
$$

where again $H$ is the accumulation of knowledge, $\alpha$ is a parameter, and $\Psi$ is a function of abatement and the knowledge stock, with the same characteristics as $\Psi$ in Eq. (11). With this specification, current abatement acts as a learning investment in knowledge, analogous to R\&D investment. The result is similar to many other LBD studies in that both the optimal carbon tax is lower at all points in time and that there may be considerably more total abatement for any given carbon tax. Analogously, for any given path of abatement, the necessary carbon tax is lower. However, as mentioned above, the effect of LBD on the slope of the optimal path of abatement is ambiguous.

A hybrid approach that includes both LBD- and R\&D-based TC has been used in a few studies. For example, Fischer and Newell (2008) model R\&D and LBD as inputs into a knowledge stock that lowers the cost of renewables in the electricity sector. The knowledge stock is modeled as a constant elasticity function of cumulative R\&D investment in knowledge, $H_{t}$, and cumulative output, $Y_{t}$, as follows:

$$
K_{t}\left(Y_{t}, H_{t}\right)=\left(\frac{Y_{t}}{Y_{1}}\right)^{k_{1}}\left(\frac{H_{t}}{H_{1}}\right)^{k_{2}}
$$

where $k_{1}$ and $k_{2}$ are parameters and where cumulative output and R\&D are measured relative to levels in a base year. This functional form implicitly assumes a complementarity between R\&D and learning, which is supported by the limited empirical evidence available (Lieberman, 1984). The accumulation of $H$ is governed by the amount of R\&D investment, and there is no R\&D depreciation; $Y$ accumulates with production experience. Fischer and Newell take considerable care in basing technological parameter values in their model on econometric studies of technological change and other evidence. A somewhat similar formulation also is used in Bahn and Kypreos (2003), who add a "two-factor" learning curve to the MERGE model (see Manne and Richels, 2004).

Many other climate change policy-modeling studies have included some form of learning-induced TC, usually with a variant of (18), including: Grübler and Messner (1998), Seebregts et al. (1999), Gritsevskyi and Nakicenovic (2000), van der Zwann et al. (2002), Anderson and Bird (1992), Papathanasiou and Anderson (2001), Castelnuovo and Galeotti (2003), Gerlagh and Lise (2003), Gerlagh and van der Zwann (2003), Jacoby et al. (2003), Messner (1997), and Mulder et al. (2003). The NEMS industrial and electricity modules also include LBD (EIA, 2003).

\section{Conclusion}

Given the considerable variety of approaches used to include ETC in climate policy models, it is clear that there is no agreement in the literature regarding a single best approach. All of the approaches discussed in this paper have their limitations, and all are approximations that miss some important phenomena underlying the complex nature of TC with important effects on the results of climate policy models. Perhaps more importantly, all struggle with an inherent lack of empirical data to calibrate model parameters convincingly. Below are some key insights from this review for consideration by both modelers

\footnotetext{
${ }^{15}$ Note this runs counter to a common argument that a gradual increase in near-term abatement is optimal in order to avoid premature obsolescence of the existing capital stock and allow more time for low-cost substitutes to be developed.
} 
and users of model results. Our focus has been on R\&D- and learning-based approaches (versus priceinduced), as most recent developments in endogenizing TC fall into these categories.

Three main points are worth emphasizing with regard to R\&D-based approaches: (1) they are most easily used in more aggregate models; (2) they engender a tension between spillovers and crowding out; and (3) the empirical evidence underlying many of the relationships in R\&D-based approaches remains somewhat weak. Each of these points will be addressed in turn.

First, R\&D-based approaches lend themselves more easily to highly aggregated, forward-looking models with an explicit production function. In this approach, R\&D is treated as an investment in a knowledge stock, which is an input into production similar to physical capital. Among aggregate models, those that consider the profit-maximization condition of firms tend to have an easier time incorporating R\&D because they more easily incorporate the divergence between social returns and private returns. ${ }^{16}$

Regardless of the model structure, the treatment of both crowding out and spillover assumptions are highly important. Several studies have spillovers that scale the output of the production function and find that the optimal carbon policy is different when spillovers are included. Spillovers have important consequences for measuring welfare effects because they represent a source of potential welfare improvements (i.e., a market imperfection).

A considerable difficulty in endogenizing TC based on R\&D lies in determining the values of the key parameters. This also is more broadly true of many of the relationships theorized in the model structures described in this paper, which have not been fully empirically validated (if at all). Choosing a functional specification that fits best within any given model, but at the same time is empirically valid, is not an easy task. Nor is it an easy task to consider both public R\&D and private R\&D. Few, if any, models attempt to address both explicitly due to the difficulties in modeling and measuring each-yet there are likely to be interactions between the two that are important to climate policy.

Distinct from the explicit R\&D pathway, many LBD-based models have sought to include an association between falling unit production costs and cumulative output or experience with a technology. Three main points are worth emphasizing with regard to LBD-based approaches: (1) they are most readily used in technology-rich models; (2) they capture an apparent empirical regularity, but there are questions about causality and extrapolation to new technologies; and (3) it is difficult to account for the direct and indirect costs of learning.

In models replete with technological specificity, adding in learning appears to be a natural way to include ETC. At the technology level, empirical evidence supports the idea of a learning effect. Moreover, including this effect appears to have important implications for climate policy, such as lower costs of achieving a given carbon-mitigation target. In some cases, adding learning also changes the slope of the optimal abatement path for a given concentration target, implying more near-term reductions, although recent work has indicated that the effect of learning on the slope of the abatement is ambiguous.

However, LBD-based TC also has substantial problems. There is always the question of the validity of extrapolating historical evidence of learning in past technologies to new technologies. In addition, learning is a "black box," leading to questions of the causality of the reduced costs. For example, is the process of learning influenced by additional R\&D investment, and, if so, is that R\&D investment counted as a cost of the policy? Similarly, does learning in one technology come at the cost of learning in other technologies, and, if so, is this opportunity cost captured in the model?

Despite these difficulties, with only a few exceptions most studies find that the ramifications and insights elucidated by incorporating ETC are important quantitatively. The methodology used to incorporate ETC ought to depend on the goal of the study: positive or normative. For positive analysis, models can be formulated in a variety of ways to generate predictions of prices and quantities that are as accurate as possible. In normative studies, it is much more important to have as transparent an accounting of opportunity costs as possible, and R\&D-based TC has some advantages in this regard.

Modelers should consider the strengths and limitations of each approach to endogenizing technological change and experiment with the approaches that best correspond to the purpose and structure of the model, keeping in mind the possible biases inherent in choosing one approach over another. Users of model results should be aware of the substantial implications that these subtle assumptions can have on model

\footnotetext{
${ }^{16}$ See Fischer and Newell (2008), who explicitly address the divergence in first-order conditions between social and firm-level optimization regarding knowledge investments.
} 
results. Perhaps most importantly, users looking to draw normative conclusions about the costs and benefits of alternate policies need to be particularly aware of the degree to which models have been ground-truthed against historic facts and trends and ensure that opportunity costs have been accounted for properly. While exceptionally promising, there is a sense that our ability to conceptually model technological change has outstripped our ability to validate the models empirically, making this an area where policymakers and other normative users need to be particularly careful.

\section{Acknowledgments}

The authors acknowledge helpful feedback from the participants of the Workshop on Technological Change and the Environment at Dartmouth College, and in particular, Karen Fisher-Vanden, David Popp, and Ian Sue Wing. We would also like to thank John Weyant and two anonymous referees for useful comments. Finally we acknowledge the U.S. Environmental Protection Agency for the financial support.

\section{References}

Acemoglu, D., 1998. Why do new technologies complement skills? Directed technical change and wage inequality. Quarterly Journal of Economics 113, 1055-1089.

Acemoglu, D., 2002. Directed technical change. Review of Economic Studies 69, 781-809.

Aghion, P., Howitt, P., 1998. Endogenous Growth Theory. MIT Press, Cambridge, MA.

Alcamo, J., Kreileman, E., Leemans, R., 1998. Global Change Scenarios of the 21st Century, Results from the IMAGE 2.1 Model. Elsevier Science, London.

Anderson, D., Bird, C.D., 1992. Carbon accumulation and technical progress-a simulation study of costs. Oxford Bulletin of Economics and Statistics 54, 1-29.

Arrow, K., 1962. The economic implications of learning by doing. Review of Economic Studies 29, 155-173.

Azar, C., Dowlatabadi, H., 1999. A review of technical change in assessments of climate policy. Annual Review of Energy and the Environment 24, 513-544.

Bahn, O., Kypreos, S., 2003. Incorporating different endogenous learning formulations in MERGE. International Journal of Global Energy Issues 19 (4), 333-358.

Barker, T., Köhler, J., 1998. Equite and ecotax reform in the EU: achieving a 10\% reduction in CO2 emissions using exise duties. Fiscal Studies 19 (4), 375-402.

Barreto, L., Kypreos, S., 1999. Technological learning in energy models: experience and scenario analysis with MARKAL and the ERIS model prototype. PSI Report 99-08.

Binswanger, H., Ruttan, V., 1978. Induced Innovation: Technology Institutions and Development. Johns Hopkins University Press, Baltimore, MD.

Böhringer, C., 1998. The synthesis of bottom-up and top-down in energy policy modeling. Energy Economics 20 (3), $234-248$.

Bollen, J., Manders, T., Veenendaal, P., 2004. How much does a 30\% emission reduction cost? CPB Netherlands Bureau for Economic Policy Analysis, The Hague.

Buonanno, P., Carraro, C., Galeotti, M., 2003. Endogenous induced technical change and the costs of Kyoto. Resource and Energy Economics 25 (1), 11-34.

Burniaux, J.M., Martin, J.P., Nicoletti, G., Oliveira, J., 1992. GREEN-A Multi-Region Dynamic General Equilibrium Model for Quantifying the Costs of Curbing CO2 Emissions: A Technical Manual, Economics and Statistics Department Working Papers. OECD, Paris, France.

Capros, P., Georgakopoulos, D., Van Regemorter, D., Proost, S., Schmidt, T.F.N., Conrad, K., 1997. European Union-the GEM-E3 General Equilibrium Model. Economic and Financial Modeling 4 (2-3).

Carraro, C., Galeotti, M., 1997. Economic growth, international competitiveness and environmental protection: R\&D and innovation strategies with the WARM model. Energy Economics 19 (1), 2-28.

Castelnuovo, E., Galeotti, M., 2003. Learning by doing vs learning by researching in a model of climate change policy analysis. FEEM Working Paper 11.2003.

Clarke, L., Weyant, J., 2002. Modeling induced technological change: an overview. In: Grübler, A., Nakicenovic, N., Nordhaus, W. (Eds.), Technological Change and the Environment. Resources for the Future Press, Washington, DC.

Dowlatabadi, H., 1998. Sensitivity of climate change mitigation estimates to assumptions about technical change. Energy Economics 20 (5-6), 473-493.

Edenhofer, O., Lessman, K., Kemfert, C., Grubb, M., Kohler, J., 2006. Induced technological change: exploring its implications for the economics of atmospheric stabilization. The Energy Journal Special Issue, 1-51.

Edmonds, J., Roop, J., Scott, M., 2000. Technology and the Economics of Climate Change Policy. Pew Center on Global Climate Change, Arlington, VA.

EIA, 2003. National Energy Modeling System: An Overview 2003. DOE/EIA-0581. Energy Information Administration, Department of Energy, Washington, DC.

Fischer, C., Newell, R., 2008. Environmental and technology policies for climate mitigation. Journal of Environmental Economics and Management 55 (2), 142-162.

Fisher-Vanden, K., Jefferson, G., Liu, H., Tao, Q., 2004. What is driving China's decline in energy intensity? Resource and Energy Economics 26 (1), 77-97.

Fisher-Vanden, K., Jefferson, G., Jingkui, M., Jianyi, X., 2006. Technology development and energy productivity in China. Energy Economics 28 (5-6), 690-705.

Gerlagh, R., Lise, W., 2003. Induced technological change under carbon taxes. Working Paper. Vrije Universiteit, Amsterdam, Netherlands. 
Gerlagh, R., van der Zwann, B., 2003. Gross world product and consumption in a global warming model with endogenous technological change. Resource and Energy Economics 25 (1), 35-37.

Goulder, L., 2004. Induced technological change and climate policy. Pew Center for Global Climate Change, Arlington, VA.

Goulder, L., Mathai, K., 2000. Optimal CO2 abatement in the presence of induced technological change. Journal of Environmental Economics and Management 39, 1-38.

Goulder, L., Schneider, S., 1999. Induced technological change and the attractiveness of CO2 abatement policies. Resource and Energy Economics 21, 211-253.

Gritsevskyi, A., Nakicenovic, N., 2000. Modeling uncertainty of induced technological change. Energy Policy 28, 907-921.

Grossman, G., Helpman, E., 1994. Endogenous innovation in the theory of growth. Journal of Economic Perspectives 8, 23-44.

Grubb, M., 1997. Technologies, energy systems and the timing of CO2 emissions abatement: an overview of economic issues. Energy Policy 25 (2), 159-172.

Grubb, M., Chapuis, T., Duong, M.H., 1995. The economics of changing course: implications of adaptability and inertia for optimal climate policy. Energy Policy 23 (4/5), 417-431.

Grubb, M., Köhler, J., Anderson, D., 2002. Induced technical change in energy and environmental modeling. Annual Review of Energy and the Environment 27, 271-308.

Grübler, A., Messner, S., 1998. Technological change and the timing of mitigation measures. Energy Economics 20, 495-512.

Grübler, A., Nakicenovic, N., Victor, D., 1999. Modeling technological change: implications for the global environment. Annual Review of Energy and the Environment 24, 545-569.

Grübler, A., Nakicenovic, N., Nordhaus, W. (Eds.), 2002. Technological Change and the Environment. Resources for the Future Press, Washington, DC.

Hicks, J., 1932. The Theory of Wages. Macmillan, London, UK.

Jacoby, H., Reilly, J., McFarland, J., 2003. Technology and technical change in the MIT EPPA model. Proceedings of the P.I. Workshop, US DOE Integrated Assessment Program, 5-6 August, Snowmass, CO.

Jaffe, A., Newell, R., Stavins, R., 2003. Technological change and the environment. In: Maler, K.-G., Vincent, J.R. (Eds.), Handbook of Environmental Economics, vol. 1. Elsevier, Washington, DC.

Jakeman, G., Hanslow, K., Hinchy, M., Fisher, B., Woffenden, K., 2004. Induced innovations and climate change policy. Energy Economics 26 (6), 937-960.

Jorgenson, D., Wilcoxen, P., 1993. Reducing US carbon emissions: an econometric general equilibrium assessment. Resource and Energy Economics 15, 7-25.

Kamien, M.I., Schwartz, N.L., 1968. Optimal induced technical change. Econometrica 36, 1-17.

Kennedy, C., 1964. Induced bias in innovation and the theory of distribution. The Economic Journal 74 (295), 541-547.

Kily, M.T., 1999. The supply of skilled labor and skill-biased technological progess. Economic Journal 109, 708-724.

Kohler, J., Grubb, M., Popp, D., Edenhofer, O., 2006. The transition to endogenous technical change in climate-economy models: a technical overview to the innovation modeling comparison project. The Energy Journal Special Issue, 17-55.

Kouvaritakis, N., Soria, A., Isoard, S., 2000. Modelling energy technology dynamics: methodology for adaptive expectations models with learning by doing and learning by searching. International Journal of Global Energy Issues 14, 104-115.

Lieberman, M.B., 1984. The learning curve and pricing in the chemical processing industries. Rand Journal of Economics 15 (2), 213-228.

Loschel, A., 2002. Technological change in economic models of environmental policy: a survey. Ecological Economics 43 (2-3), 105-126.

Lucas, 1988. On the mechanics of economic development. Journal of Monetary Economics 100, 223-251.

Lucas, R., 1976. Econometric policy evaluation: a critique. Carnegie-Rochester Conference Series on Public Policy 1, 19-46.

MacCracken, C., Edmonds, J., Kim, S., Sands, R., 1999. The economics of the Kyoto protocol. The Energy Journal 25-72 Special Issue.

Manne, A., Barreto, L., 2004. Learning-by-doing and carbon dioxide abatement. Energy Economics 26, 621-633.

Manne, A., Richels, R., 1992. Buying Greenhouse Insurance: The Economic Costs of CO2 Emission Limits. MIT Press, Cambridge, MA.

Manne, A., Richels, R., 2004. The impact of learning-by-doing on the timing and costs of CO2 abatement. Energy Economics 26, 603-619.

McKibbin, W., Wilcoxen, P., 1993. The global consequences of regional environmental policies: an integrated macroeconomic, multisectoral approach. In: Kaya, Y., Nakicenovic, N., Nordhaus, W. (Eds.), Costs, Impacts, and Benefits of CO2 Mitigation. IIASA, Laxenburg, Austria.

Messner, S., 1997. Endogenized technological learning in an energy systems model. Journal of Evolutionary Economics 7 (3), $291-313$.

Mulder, P., de Groot, H., Hofkes, M., 2003. Explaining slow diffusion of energy-saving technologies; a vintage model with returns to diversity and learning-by-using. Resource and Energy Economics 25 (1), 105-126.

Neij, L., 1997. Use of experience curves to analyze the prospects for diffusion and adoption of renewable energy technology. Energy Policy 23 (13), 1099-1107.

Newell, R., Jaffe, A., Stavins, R., 1999. The induced innovation hypothesis and energy-saving technological change. The Quarterly Journal of Economics 114 (3), 941-975.

Nordhaus, W., 1994. Managing the Global Commons: The Economics of Climate Change. MIT Press, Cambridge, MA.

Nordhaus, W., 2002. Modeling induced innovation in climate change policy. In: Grubler, A., Nakicenovic, N., Nordhaus, W. (Eds.), Technological Change and the Environment. Resources for the Future Press, Washington, DC.

Nordhaus, W., Yang, Z., 1996. A regional dynamic general-equilibrium model of alternative climate-change strategies. American Economic Review 86 (4), 741-765.

Oravetz, M., Dowlatabadi, H., 1995. Is there autonomous energy efficiency improvement? Working Paper 1995.12. Carnegie Mellon University, Pittsburgh, PA.

Otto, V., Loschel, A., Reilly, J., 2006. Directed technical change and climate policy. MIT Joint Program on the Science and Policy of Global Change Report 134, Cambridge, MA.

Papathanasiou, D., Anderson, D., 2001. Uncertainties in responding to climate change: on the economic value of technology policies for reducing costs and creating options. The Energy Journal 23 (3), 79-114.

Pizer, W., 1999. The optimal choice of climate change policy in the presences of uncertainty. Resource and Energy Economics 21 (3-4), 255-287.

Popp, D., 2001. The effect of new technology on energy consumption. Resource and Energy Economics 23 (3), 215-239.

Popp, D., 2002. Induced innovation and energy prices. American Economic Review 92 (1), 160-180. 
Popp, D., 2003. Lessons from patents: using patents to measure technological change in environmental models. NBER Working Paper 9978. National Bureau of Economic Research, Cambridge, MA.

Popp, D., 2004. ENTICE: endogenous technological change in the DICE model of global warming. Journal of Environmental Economics and Management 48, 742-768.

Popp, D., 2005. Lessons from patents: using patents to measure technological change in environmental models. Ecological Economics $54(2-3), 209-226$.

Popp, D., 2006a. ENTICE-BR: the effects of backstop technology R\&D on climate policy models. Energy Economics 28, 188-222.

Popp, D., 2006b. Innovation in climate policy models: implementing lessons from the economics of R\&D. Energy Economics 28 (5-6), 596-609.

Romer, P., 1990. Endogenous technological change. Journal of Political Economy 98 (5), S71-S102.

Rosenberg, N., 1982. Inside the Black Box: Technology and Economics. Cambridge University Press, Cambridge, UK.

Ruttan, V., 2002. Sources of technical change: induced innovation, evolutionary theory and path dependence. In: Grubler, A., Nakicenovic, N., Nordhaus, W. (Eds.), Technological Change and the Environment. Resources for the Future Press, Washington, DC.

Schneider, S., Goulder, L., 1997. Commentary: achieving low-cost emissions targets. Nature 389, 13-14 (4 September).

Seebregts, A., Kram, T., Schaeffer, G., Stoffer, A., Kypreos, S., Barreto, L., Messner, S., Schrattenholzer, L., 1999. Endogenous Technological Change in Energy Systems Models: Synthesis of Experience with ERIS, MARKAL and MESSAGE, Technical Report. Netherlands Research Foundation ECN.

Smulders, S., de Nooij, M., 2003. The impact of energy conservation on technology and economic growth. Resource and Energy Economics 25 (1), 59-79.

Sue Wing, I., 2001. Induced Technological Change in Computable General Equilibrium Models for Climate-Change Policy Analysis. $\mathrm{PhD}$ Dissertation. Massachusetts Institute of Technology, Cambridge, MA.

Sue Wing, I., 2003. Induced technical change and the cost of climate policy. Joint Program on the Science and Policy of Global Change Report no. 112. Massachusetts Institute of Technology, Cambridge, MA.

Sue Wing, I., 2006. Representing induced technological change in models for climate policy. Energy Economics 28, 539-562.

Sue Wing, I., 2008a. Induced Technological Change: Firm Innovatory Responses to Environmental Regulation. Unpublished Manuscript available at http://people.bu.edu/isw/.

Sue Wing, I., 2008b. Explaining the declining energy intensity of the U.S. economy. Resource and Energy Economics 30, 21-49.

Sue Wing, I., Popp, D., 2006. Representing endogenous technological change in models for climate policy analysis: theoretical and empirical considerations. In: Managing greenhouse gas emissions in California. California Climate Change Center, Berkeley, CA.

van der Zwann, B., Gerlagh, R., Klaassen, G., Schrattenholzer, L., 2002. Endogenous technological change in climate change modeling. Energy Economics 24, 1-19.

van Zon, A., Yetkiner, I.H., 2003. An endogenous growth model with embodied energy-saving technical change. Resource and Energy Economics 25 (1), 81-103.

Vollebergh, H., Kemfert, C., 2005. The role of technological change for sustainable development. Ecological Economics 54, $133-147$.

Weyant, J., 2004. Introduction and overview: energy economics special issue EMF 19 study on technology and global change policies. Energy Economics 26, 501-515.

Weyant, J., Olavson, T., 1999. Issues in modeling induced technological change in energy, environmental, and climate policy. Environmental Modeling and Assessment 4 (2\&3), 67-85.

Wright, T.P., 1936. Factors affecting the costs of airplanes. Journal of Aeronautical Sciences 3, 122-128. 